\title{
RELATIVISMO LINGÜÍSTICO E O ENSINO DE LÍNGUA ESTRANGEIRA
}

\author{
Rodrigo Tadeu GONÇALVES
}

\section{Resumo}

Neste artigo, pretendo desenvolver algumas questões sobre o modo como as concepções de linguagem, a educação lingüística e a reflexão crítica sobre os processos complexos envolvidos no uso e teorização sobre a linguagem podem trazer benefícios ao professor de línguas estrangeiras. Para tanto, discutirei as noções de relativismo lingüístico e etnocentrismo, ligadas à idéia de que, com freqüência, as separações tácitas e invisíveis entre as cosmovisões do teórico, do prático, do professor e do pesquisador são profundamente prejudiciais para o processo de ensino e aprendizagem de LEs.

Palavras-chave: Relativismo Lingüístico; Etnocentrismo; Ensino de Línguas Estrangeiras.

\begin{abstract}
In this article I intend to discuss some issues regarding the ways in which conceptions of language, linguistic education and critical awareness may produce benefits to the teachers of foreign languages. In order to do that, I will discuss the notions of linguistic relativity and ethnocentrism tied to the idea that the presence of tacit and invisible frontiers among the worldviews of the theorists, the practitioners, the teachers and the scholars can be deeply harmful to the process of teaching and learning foreign languages.
\end{abstract}

Keywords: Linguistic Relativity; Ethnocentrism; Foreign Language Teaching.

\section{O Relativismo Linguístico}

O relativismo, de maneira geral, consiste em afirmar que algum aspecto relacionado a temas como verdade, razão, experiência, percepção, é relativo a alguma outra coisa. 
Em sua formulação, a versão geral do relativismo se dá da seguinte maneira:

algo, s, é verdadeiro para $\psi$ e s é falso para $\varphi$.

O relativismo lingüístico (doravante, $\mathrm{RL}$ ) pode ser entendido em termos gerais como a proposta de que a língua que falamos influencia de alguma forma o modo como pensamos sobre a realidade. Trata-se de uma proposta que se apresenta de muitas formas ao longo da história do pensamento sobre a linguagem, e muitas das posições relativistas quanto à linguagem não são necessariamente explícitas.

Formulando a hipótese de modo a encaixá-la no modelo geral de relativismo exposto acima, podemos apresentá-la da seguinte maneira:

- a variável independente na relação é a língua.

- as variáveis dependentes na relação são a experiência, as crenças, a percepção, a visão de mundo, os conceitos.

Assim, o princípio do relativismo lingüístico, de modo geral, defende a posição de que a percepção, as crenças, os conceitos, enfim, a visão de mundo de povos diferentes variam conforme variem as línguas que eles falam. Postulada desta forma, a hipótese é bastante geral e atraente, pois é fácil aceitar que línguas pertencentes a famílias lingüísticas muito diferentes sejam, de fato, veículos de realidades bastante diferentes. Não somente pelo que as próprias línguas fazem, mas especialmente porque, seguindo as explicações para outras formas de relativismo acima, a realidade não nos é dada objetivamente: ela, antes, passa pelo filtro de nossa percepção, e, então, pode ser categorizada e construída pela nossa linguagem. Não há observação neutra da realidade, e, supõem os relativistas, línguas muito diferentes podem ser veículos muito diferentes para a categorização de realidades muito diferentes. A versão mais difundida da hipótese do relativismo lingüístico é aquela que tem sido atribuída comumente a Edward Sapir e Benjamin Lee Whorf.

É certo, no entanto, que as propostas relativistas quanto à linguagem são muito variadas, e também é certo que uma hipótese tão impactante, ainda que genericamente exposta como foi acima, precisaria de evidência empírica sólida para se sustentar. Assim, vejamos como é possível separar algumas das teses mais específicas de dentro 
da tese maior, incluindo a parte comumente vista como negativa pelos críticos do relativismo lingüístico, o chamado determinismo lingüístico, seguindo Gumperz \& Levinson (1996: 23):

a) Diferença lingüística: as línguas diferem substancialmente nos seus sistemas de significados e estrutura gramatical.

b) Determinismo lingüístico: as categorizações lingüísticas determinam aspectos de categorização não linguíística, memória, percepção ou pensamento em geral.

i. Determinismo lingüístico forte: conceitos não codificados lingüisticamente são inacessíveis.

ii. Determinismo lingüístico fraco: conceitos que forem codificáveis linguisticamente são favorecidos ou facilitados.

A partir de (a) e (b), Gumperz \& Levinson chegam à seguinte formulação da Hipótese do Relativismo Lingüístico:

$\mathrm{Se}$

(i) existem diferenças nas categorizações lingüísticas nas línguas e

(ii) as categorizações lingüísticas determinam aspectos do pensamento dos indivíduos,

Então

(iii) aspectos do pensamento dos indivíduos diferem nas diferentes comunidades lingüísticas de acordo com a língua que elas falam.

Versões intuitivas e populares do relativismo lingüístico com relação ao léxico das línguas são encontradas muito comumente na mídia ou em discursos sobre a língua (proferidos por especialistas ou não-especialistas com bastante frequiência). Trata-se da visão de relativismo geralmente associada à suposta existência, em certas línguas, de um número muito maior de palavras para designar certas coisas que em outra língua são designadas por um número relativamente menor de palavras. $\mathrm{O}$ exemplo clássico é o sempre citado caso da língua esquimó, que tem um número enorme (e que varia de autor para autor ou de ocasião para ocasião) para designar o que nós designamos por neve.

Esse primeiro exemplo é claramente o mais popular e o mais, digamos, intuitivo. Um texto do jornalista e escritor Sérgio Augusto defende que, em português brasileiro, 
temos tantos ou mais sinônimos para "bunda" do que os esquimós têm para neve. O que representam esses tipos de afirmações para quem as propõe? Naturalmente, uma língua que tenha tantas palavras para se referir à "mesma coisa" é certamente uma língua que segmenta a realidade de maneira diferente de uma língua que não tenha tantos termos para aquela mesma coisa ${ }^{1}$. Entretanto, cabem algumas perguntas, tais como: (i) Qual é o objetivo desse tipo de afirmação? (ii) A influência causal representada por esse tipo de afirmação "empírica" é a que favorece a hipótese do RL? (iii) Essas palavras todas se referem à "mesma coisa" a que outra língua se refere com menos palavras?

Respondamos por partes: uma boa resposta para (i) é que quem profere esse tipo de afirmação, em geral baseada em dados subjetivos, aproximados e enviesados (afinal, não há, até onde procuramos, estudos sistemáticos sobre esses conceitos que são designados por tantas palavras, e, no caso da neve dos esquimós, o número de palavras varia de estudo para estudo, de seis a duzentas e tantas (cf. Pullum, 1991), ou procura valorizar positiva ou negativamente a língua que apresenta todas as inúmeras palavras, ou procura apresentar o dado como algo "curioso", "intrigante", "interessante", o que, por si só, já é um modo de valorar a língua em questão, de forma etnocêntrica, colocando a língua do que profere a afirmação em uma situação de "normalidade": ora, se o falante de inglês afirma que os esquimós têm duzentas palavras para falar de "neve", imediatamente ele espera gerar em seu interlocutor a sensação de estranhamento e de maravilhamento com uma cultura exótica, incrível, que enxerga a realidade de maneira tão especial (não é à toa que, no caso dos esquimós, outras informações antropológicas "curiosas" costumam acompanhar a das duzentas neves: dizem que, se você visitar um esquimó e não aceitar que ele ofereça sexualmente sua esposa para você, você estará cometendo uma grande ofensa cultural), além de, ao mesmo tempo, gerar em sua audiência uma sensação de segurança e conforto por fazer parte de uma cultura saudável e normal, que tem poucas palavras para neve porque se preocupa com coisas mais importantes. Afinal, não é normal dividir a esposa com os hóspedes. No caso da lista de 200 sinônimos para "bunda" no português brasileiro, fica claro que o objetivo é o mesmo, apenas invertidas as posições da cultura do outro e a do eu: a intenção de crítica social disfarçada pelo humor é exatamente reforçada pelo fato de que, supostamente, nenhuma outra língua tem tantas palavras para se referir ao mesmo

\footnotetext{
${ }^{1}$ Há, aqui, um problema que não está nem perto de ser resolvido pelos proponentes das versões intuitivas e populares do relativismo lexical: é bastante difícil definir o que seja a "mesma coisa" em termos semânticos.
} 
conceito (assim como nenhuma outra língua, dizem muitos, em tom de curiosidade antropológica ufanista, tem um equivalente para a palavra "saudade", sem nenhuma possibilidade de sustentação empírica ou teórica).

Sobre (ii), a resposta é complexa. Não é necessariamente verdade que as afirmações sobre a existência de múltiplas palavras correspondentes ao mesmo conceito em uma língua e a inexistência do mesmo número de sinônimos em outra língua represente uma corroboração do RL. Podemos pensar, de maneira muito mais simples, que se uma língua desenvolve mais vocabulário para lidar com certas áreas de conhecimento, campos semânticos ou conceitos salientes, pode ser que esteja ocorrendo exatamente o contrário do RL clássico: pode ser, simplesmente, que a língua receba a influência da cultura e da sociedade, e não o contrário. Afinal, é bastante óbvio que, se o latim clássico não tem palavra que signifique a mesma coisa que o termo iPod, é mais provável que a ausência do referente na sociedade romana causasse a ausência da palavra do que o caminho contrário. O contato mais intenso dos esquimós com a neve obviamente gera a necessidade de maior distinção lexical para eles do que para os falantes de inglês ou português, o que, claramente, não significa dizer que não seríamos capazes de perceber as diferenças que os esquimós percebem nos tipos de neve.

Quanto a (iii), finalmente, voltamos ao argumento da traduzibilidade: os esquimós estão falando de "neve" ou de snow quando usam suas $n$ palavras para "neve"? Obviamente, de nenhuma das duas. Ao pensarmos dessa forma, estamos incorrendo novamente no problema etnocêntrico: o universo conceitual de um esquimó não é necessariamente idêntico ao do falante de português ou inglês, mas também não é necessariamente incomensurável ${ }^{2}$. O esquimó pode ver diferenças que não vemos na neve, mas essas diferenças podem ser explicadas ou traduzidas: é a "neve que vem com o vento", a "neve que se parece com gelo", a "geada", a "nevasca", a "neve pisada pelas patas dianteiras do urso polar" e assim por diante. Os exemplos de tradução deixam duas coisas claras: em primeiro lugar, podemos traduzir os inúmeros termos esquimós para "neve"; segundo, não há (e nem é necessário que haja) uma correspondência biunívoca total entre termos de uma língua e de outra, como se houvesse um inventário universal de conceitos aos quais as línguas tivessem que necessariamente fazer corresponder uma palavra para cada item.

\footnotetext{
${ }^{2}$ Longe de propor uma teoria da relação entre universos conceituais de falantes de diferentes línguas, o que se pretende com esse argumento é mostrar que não é necessariamente o fato de que os esquimós possuem tantas palavras a mais para se referir ao que nós denominamos de "neve" que geraria a incomensurabilidade entre os universos conceituais.
} 
Ao fim da discussão dessa visão simples e intuitiva do relativismo lexical, esperamos que esteja claro, em especial, que essa visão é trivial e de pouco valor heurístico, já que ela não diz muita coisa sobre as diferenças entre as línguas, e não corrobora necessariamente nem o RL nem o universalismo lingüístico.

No entanto, há discussões interessantes e importantes sobre o RL no campo das diferenças lexicais entre as línguas. Uma das mais freqüentemente citadas e resenhadas é a que diz respeito aos termos de cor. As línguas têm conjuntos diferentes de termos de cor, e os pesquisadores procuram verificar como isso afeta a cognição dos falantes.

Inicialmente, a questão é complicada, já que a posição do RL prevê que o fato de as línguas variarem em seus inventários de termos de cor causaria diferenças na capacidade de as pessoas lidarem com as cores extra-lingüisticamente. Um estudo experimental importante de Brown \& Lennenberg (1954, apud Cole \& Scribner, 1974: 44) sobre a influência das diferenças lexicais nos grupos falantes de diferentes línguas propõe que a facilidade com a qual uma distinção é expressa em uma língua diz respeito à freqüência com que o referente discriminado é necessário e requisitado no dia-a-dia do grupo. Isso explicaria a maior quantidade de palavras para "neve" na língua dos esquimós, por exemplo.

O outro conceito importante de que Brown \& Lennenberg lançaram mão foi o de codificabilidade, que diz respeito ao fato de que certas experiências são mais facilmente lembradas em testes de memória se a língua em questão apresentar palavras para elas. Por isso, argumentam os autores, as línguas que apresentam mais termos específicos para cores levam os seus falantes a codificarem as experiências com cores com mais precisão.

Os experimentos dessa época consistiam basicamente em apresentar fichas coloridas aos sujeitos, que deveriam nomear a cor o mais rápido que pudessem. No caso de Brown \& Lennenberg, as cores com nomes mais longos eram lembradas mais lentamente, e as cores mais rapidamente lembradas correspondiam a cores cujos nomes eram mais acessíveis aos indivíduos. Num experimento posterior, Lennenberg \& Roberts (1956, apud Cole \& Scribner, 1974: 46), os índios norte-americanos zuni foram testados da mesma forma, mas, como sua língua não distingue amarelo de laranja, a previsão de que eles teriam mais dificuldade em lembrar-se dessas cores se confirmou. Naturalmente, tais resultados favoreciam uma versão fraca do RL.

No entanto, as décadas de 1950 e 1960 viram muita pesquisa experimental quanto aos termos de cores e, num estudo clássico, Berlin \& Kay (1969) pediram a 
falantes de 20 línguas para escolherem entre as fichas coloridas exemplos das cores correspondentes aos termos básicos de cores de suas línguas. Em seguida, eles solicitaram que os sujeitos selecionassem outras fichas que pudessem ser chamadas pelos mesmos nomes daquelas escolhidas como pertencentes ao grupo das cores básicas de sua língua. Os resultados foram interessantes: os falantes de todas as línguas organizaram as cores, em geral, em torno de onze cores básicas chamadas focais: oito cromáticas (vermelho, amarelo, verde, azul, marrom, laranja, rosa e roxo) e três acromáticas (preto, branco e cinza ${ }^{3}$ ). Isso aponta para uma suposta universalidade no modo como as línguas constroem seu sistema de cores: ainda que a língua tenha apenas dois ou três termos de cores, o modo como elas classificam as cores é universal: as línguas não variam tanto assim no quesito arbitrariedade no inventário de termos de cores.

Muito se pesquisou sobre termos de cores, tanto do lado relativista quanto do lado universalista, e, por exemplo, Lucy (1997: 300) lista uma série de experimentos mais recentes que tentam mostrar que a metodologia e o modo de descrição lingüística presentes nos experimentos daquela época foram reformulados, apontando para outras conclusões.

Paul Kay, mesmo, em artigos mais recentes, reavalia alguns dos resultados a que chegara na ocasião. Kay \& Regier (2006: 52) afirmam que as novas pesquisas na área da cognição das cores têm levado a conclusões que vão além do debate tradicional relativismo versus universalismo, pois, ao mesmo tempo em que respondem negativamente à pergunta "os nomes das cores nas línguas do mundo são meramente convenção lingüística arbitrária?", respondem afirmativamente à pergunta “as diferenças entre as línguas na nomeação das cores causam diferenças correspondentes na cognição?”. Segundo Kay \& Regier, duas respostas afirmativas caracterizavam as pesquisas com conclusões favoráveis ao RL, enquanto que as pesquisas de conclusões universalistas, como as do grupo do próprio Kay nos anos 60 e 70, respondiam a ambas as perguntas negativamente.

O foco das pesquisas sobre termos de cores, mais recentemente, se afasta dos moldes tradicionais e procura correlacionar a quantidade de termos de cores das línguas ao grau de industrialização da sociedade em questão (quanto maior, mais termos de cores estão disponíveis) ou à quantidade de radiação ultra-violeta a que os falantes de

\footnotetext{
${ }^{3}$ Correspondentes aos termos de cores do inglês: red, yellow, green, blue, brown, orange, pink, purple, black, white e gray).
} 
línguas de certos grupos são expostos (por exemplo, línguas próximas da linha do Equador tendem a não apresentar termos distintos para verde e azul, segundo Lindsey \& Brown (2002, apud Kay \& Regier, 2006)).

Kay \& Regier (2006) apresentam ainda uma extensa lista de pesquisas recentes que apontam para caminhos diferentes daqueles apresentados nos estudos clássicos de diferenças nos vocabulários das cores nas línguas.

Montgomery (1985), em capítulo dedicado à questão da linguagem e representação, apresenta o RL também em termos gerais, com os mesmos exemplos ligados ao relativismo lexical, aos termos de cores, e apresenta as dificuldades costumeiramente atribuídas às visões relativistas fortes: ausência de evidência empírica para as teses, traduzibilidade etc. No entanto, o autor apresenta uma discussão bastante interessante sobre os modos mais amenos da hipótese relativista e a sua relação com a idéia de que a linguagem é responsável pela possibilidade de representação do mundo para as nossas mentes. Em suas palavras:

O que a posição relativista enfatiza, então, apesar de certas dificuldades associadas a ela, é que o mundo não é dado para nós direta e claramente na experiência. Ao apreender, compreender e representar o mundo nós inevitavelmente empregamos formulações lingüísticas. (Montgomery, 1985: $176)^{4}$

Ou, ainda, de modo mais claro:

A língua sempre ajuda a selecionar, arranjar, organizar e avaliar a experiência, mesmo quando estamos menos conscientes de fazê-lo. Nesse sentido, a representação é sempre interessada: as palavras escolhidas são selecionadas de um conjunto determinado para a situação em questão e foram previamente moldadas pela comunidade a que o falante pertence, ou por partes dela. (loc. cit.)

Para exemplificar a importância que a língua particular tem ao veicular a possibilidade de representação para o indivíduo, funcionando antes como uma espécie de lente para acessar a realidade do que como uma camisa-de-força (metáfora usualmente empregada para designar as versões mais fortes do RL, dada a idéia de ver a língua como "prisão" do pensamento), Montgomery discute em especial dois casos em que o vocabulário de uma língua apresenta modos interessantes de representação. O primeiro é o da representação de gênero que se pode perceber através de vocábulos

\footnotetext{
${ }^{4}$ As traduções de trechos em língua estrangeira neste artigo são de minha responsabilidade.
} 
ligados à noção de "homem" e "mulher" em inglês. Uma lista breve de pares como king - queen, courtier - courtesan, master - mistress, sir - madam mostra que, ainda que fossem anteriormente pares neutros quanto ao significado (rei e rainha, membro da corte masculino e feminino, senhor e senhora da casa, senhor e senhora), na época em que publicou o texto se apresentavam alterados de maneira interessante: queen assume o sentido de "travesti", courtesan de "prostituta de luxo", mistress de "amante ilícita" e madam de "senhora de prostíbulo", enquanto que suas contrapartes masculinas continuavam a manter apenas o sentido original, geralmente ligado a posições respeitosas na sociedade. Sendo a apresentação não muito diferente de outras línguas aparentadas, como o português, que apresentam algumas dessas diferenças (como a do sentido pejorativo de "cortesã”), o que Montgomery pretende com a apresentação desses itens particulares é mostrar que, ainda que inconscientemente, a língua desenvolve as especificidades de significado que seus usuários usam e pelas quais eles são afetados, numa espécie de jogo circular em que usuários/sociedade alteram a língua, que deve ser usada por outros usuários, de modo que, por sua vez, recebem a influência daquelas alterações anteriores.

É mais fácil entender a argumentação de Montgomery se analisarmos seu segundo exemplo. Trata-se de uma breve análise do vocabulário de representação de armamentos nucleares no inglês norte-americano (Montgomery, 1985: 179). Inicialmente, o autor apresenta uma lista de expressões fortemente eufemísticas, tais como collateral damage para "matar população civil" ou flexible response para "capacidade de executar todos os tipos de ataque". Assim, segundo o autor, "tais expressões têm o efeito de anestesiar as pessoas com relação à realidade completa a que se referem" (loc. cit.). Assim, as expressões acabam sendo até mesmo transformadas em siglas ou acrônimos, de forma a perderem ainda mais seu sentido mais bruto que traz aos usuários da língua a "realidade" mais crua. Além disso, Montgomery constata que, ao longo do processo de criação de expressões eufemísticas para o vocabulário ligado a guerras nucleares, os norte-americanos deixaram de usar especificamente a palavra bomb. Palavras como device (dispositivo), weapon (arma), arsenal são empregadas em substituição a bomb como substantivo ou verbo, mas apenas em contextos em que a bomba em questão é nuclear e americana. Se há um atentado vindo de fora, usam-se as expressões car bombs, the embassy bombing etc. O interessante do exemplo de Montgomery, ainda que de um livro publicado em 1985, é que, relativisticamente falando, não apenas a língua obriga, de certa forma, os usuários a representar a realidade 
de maneira enviesada de modo que os usuários não sintam todo o peso que a palavra bomb carrega quando ligada a ações e decisões de seu próprio governo, mas há também a interessante diferença da relação língua — cultura quando passamos para outra língua, que não apresenta a restrição ao uso de "bomba" no contexto de armamentos nucleares, como é o caso do português. No nosso caso, vemos que não apenas a sociedade não levou a essa especificidade, como também não é um problema para os usuários do português usarem tanto "bomba" quanto "arma" ou "dispositivo", nesse contexto. Isso nos leva a uma interessante discussão que, de certa maneira, coloca em foco o sentido da relação causal entre língua/cultura e pensamento: se o inglês não usa mais bomb para armas nucleares, deve ter havido um movimento, consciente ou inconsciente, de mudança e criação que levaram os falantes dessa língua a preferirem (voluntariamente ou não) as formas eufemísticas. Não é mais necessariamente verdade que o sentido da relação causal seja da língua para a cognição/percepção, mas, aparentemente, o contrário pode vir antes, num esforço consciente e possivelmente político ou volitivo em algum sentido, para gerar a influência posterior da língua nos usuários: escusandonos de qualquer teoria da conspiração, o que parece haver aqui é um movimento inicial de eufemização por parte das camadas da sociedade interessadas na viabilidade do projeto nuclear, em primeiro lugar, que sistematicamente modela o sistema lingüístico de modo a excluir dele as nuances negativas de certos tipos de expressões ou vocábulos. É este projeto, inicialmente, com seus resultados possivelmente positivos, que leva à mudança na língua que, por sua vez, exerce influência na grande massa de usuários. Trata-se de uma espécie de círculo relativístico.

Esse ponto não difere muito de, por exemplo, a presidência norte-americana nomear o projeto de invasão militar no Iraque como "cruzada contra o mal" ou de o Grande Irmão tentar purificar a língua de expressões possivelmente subversivas no romance 1984 de George Orwell. A discussão fica suspensa por aqui, já que, em geral, esse tipo de visão mais fraca do RL confunde os sentidos da relação causal de influência entre língua e pensamento e acaba defendendo algo um pouco inconsistente. No entanto, essa é uma versão do RL interessante de se defender, se estabelecida e analisada com cuidado, aliada à discussão sobre aspecto criativo ou constitutivo da linguagem que faço em outro lugar (Gonçalves, 2008).

Um dos críticos contemporâneos mais ferrenhos da abordagem relativista clássica de Benjamin Lee Whorf é o cientista cognitivo Steven Pinker. Em vários de 
seus livros, Pinker estabelece críticas severas contra as versões fortes do RL e também diminui a importância dos achados experimentais sobre as versões mais leves do RL ${ }^{5}$.

Em O Instinto da Linguagem (2002, $1^{\text {a }}$ edição em inglês de 1994), Pinker classifica a hipótese do relativismo lingüístico como um absurdo convencional, daqueles que se parecem com algo que contraria o senso-comum, que todos já ouviram falar e imaginam se tratar de algo "comprovado cientificamente", de acordo com o jargão da retórica fraca do cientificismo neo-positivista. Junto com a hipótese do RL encontra-se, por exemplo, o absurdo convencional de que usamos apenas uma pequena porcentagem do nosso cérebro ou que as mensagens subliminares nos fazem comprar coisas (cf. Pinker, 2002: 62) - o que talvez possamos classificar como "lendas urbanas da ciência”.

A partir daí, Pinker associa a idéia do RL a Sapir e a Whorf, imputando a este a responsabilidade por ter tornado popular a idéia determinista da versão forte do RL. Pinker classifica a história do desenvolvimento das teses relativistas quanto à linguagem como "não intencionalmente cômica" (loc. cit., p. 64), e as critica com um certo tom de complacência arrogante, afirmando que agora que os cientistas podem de fato ter acesso ao cérebro humano na pesquisa sobre a mente humana, as hipóteses do RL não podem mais se sustentar.

Chegando finalmente ao que Pinker nos diz sobre o "estudioso amador" Whorf, a crítica não é tão diferente daquela que desenvolvi nas páginas acima: ela diz respeito fundamentalmente ao tratamento dado aos exemplos e à derivação direta do comportamento lingüístico de sociedades estranhas de modos de pensamento radicalmente diferentes. Iniciando a discussão, Pinker retoma o exemplo de Whorf sobre o tambor de gasolina "vazio", e o faz ao considerar que, se o vapor combustível que preenchia o volume do tambor é transparente, o que causou o acidente foi a visão, e não a linguagem do acidentado.

Outros pontos importantes sobre a argumentação de Whorf questionados por Pinker dizem respeito ao modo como este passa de exemplos de línguas exóticas traduzidos para o inglês para a tese de que os falantes destas línguas pensam diferentemente de nós. Inicialmente, Pinker cita estudos de Lennenberg e Brown que afirmavam que Whorf não tivera sequer contato com os falantes apache, e que a

\footnotetext{
${ }^{5}$ Curiosamente, para Adam Schaff, em 1964 (na tradução que utilizamos, Schaff, 1974: 110), o lado mais positivo do trabalho de Whorf é a "verificação empírirca" que ele forneceu à tese básica do RL: "o mérito de Whorf consiste justamente em ter empreendido essas verificações empíricas"
} 
argumentação é toda baseada na gramática de suas línguas. Assim, a tradução dos exemplos auxilia a estabelecer a ponte entre língua diferente - mente diferente: Pinker compara a tradução de "Esta primavera está chuvosa" em inglês para "Como água, ou primaveras, a brancura move-se para baixo" (já discutimos esse exemplo acima, e Pinker afirma que, de acordo com a glosa do próprio Whorf, ele poderia propor uma tradução bem menos absurda para a sentença: "Coisa clara - água - está caindo") com um inventado de acordo com as mesmas idéias de produção de efeito severo de estranheza: "He walks [Ele está andando]" poderia se tornar "As solitary masculinity, leggedness proceeds" ("Enquanto solitária masculinidade, dotado de pernas prossegue" é a tradução dada em Pinker (2002: 67)). Mais uma vez se percebe que Whorf pode ter tratado os exemplos de forma negligente, inclusive pela falta de cuidado na apresentação da gramática e dos exemplos de forma sistemática, através de glosas claras, e não apenas através de traduções distorcidas e convolutas, que, naturalmente, acentuam a impressão de incomensurabilidade.

A questão dos termos de cor também é criticada por Pinker (2002: 68). Os argumentos de Pinker são fisiológicos: os olhos registram o fluxo contínuo das cores através de três tipos de pigmentos que nossos olhos ligam aos neurônios, de modo que não há, possivelmente (para Pinker, “seria ridículo pensar assim”), argumentação que consiga ligar as diferenças lingüísticas constatadas por Whorf quanto aos termos de cores à influência direta destes nos processos neurofisiológicos dos seres humanos.

Um último ponto é o do vocabulário esquimó, que Pinker discute se utilizando do famoso artigo de Geoffrey Pullum sobre a assim chamada Grande Farsa do Vocabulário Esquimó (Pullum, 1991: 159-171). Para Pullum, Whorf foi, juntamente com Boas, responsável por popularizar a crença de que os esquimós têm muitas palavras diferentes para "neve", o que seria prova inconteste de que eles pensam diferente. Pinker e Pullum nos lembram do ponto já mencionado que diz que, ao invés de caridosa e igualitária, esse tipo de abordagem antropológica acaba por ter o irônico resultado de nos fazer olhar para o outro, afastado da nossa cultura, como diferente de nós de um modo inferior, cf. Pinker (2002: 71):

\footnotetext{
6 "It is a dripping spring". A tradução de Manuel Reis em Schaff (1974: 119) traduz a sentença como "É uma fonte que brota", enquanto que Claudia Berliner, traduzindo Pinker (2002: 66), escolhe "Esta primavera está chuvosa." Prefiro a tradução com "fonte" porque na "glosa" de Whorf parece haver uma aposição explicativa em "as water, or springs (...)". No entanto, é curioso como o próprio exemplo original de Whorf em inglês é tão estranho que nem mesmo sua glosa para o próprio inglês, nem as traduções em publicações em português resolvem o problema do sentido da sentença. Que modo de pensar incrível, o de Whorf! Que exemplo tão peculiar!
} 
Que irônica deturpação! A relatividade lingüística é um produto da escola de Boas, como parte de uma campanha para mostrar que culturas não letradas eram tão complexas e sofisticadas como as européias. No entanto, as anedotas supostamente destinadas a ampliar as idéias devem seu caráter atraente a uma sensação de superioridade que leva a tratar a psicologia de outras culturas como estranhas e exóticas [sic] em comparação com a nossa. ${ }^{7}$

O texto de Pullum é bastante importante para ligar a Grande Farsa a Whorf, e nos apresenta uma visão simultaneamente cruel e respeitosa sobre ele:

\begin{abstract}
Neste capítulo, (...) sou bastante cruel com a memória daquele belo lingüista amador. (...) Whorf tem um lugar duradouro na história da lingüística, um lugar a que poucos de nós podem aspirar. Basicamente, ele é responsável por abrir o nosso acesso a uma língua inteira que tinha sido anteriormente inacessível (a forma clássica do mais que está por trás dos hieróglifos maias até que Whorf os decifrou); ele cunhou termos duradouramente úteis ("alofone" é um exemplo) e apresentou novos e intrigantes conceitos (o conceito de criptotipo, por exemplo); e ele executou trabalhos acadêmicos importantes quase inteiramente sem posições financiadas no mundo acadêmico - um feito incomum na época, e quase inexistente hoje. (Pullum, 1991: 160)
\end{abstract}

Comparando a farsa do vocabulário do esquimó ao Alien do filme famoso e a antropóloga Laura Martin (que dedicou anos de estudos para mostrar que se trata de uma farsa, estudos que Pullum procura reavivar com seu texto) à atriz Sigourney Weaver no mesmo filme, Pullum vê em Whorf um catalisador da produção de monstros, já que seu texto de 1940 Science and linguistics foi citado e comentado de modo que, para Pullum, "não se poderia queimá-los todos com o mesmo lança-chamas"8 (loc. cit., p. 163). Whorf inflou a proposta de Boas de os esquimós terem quatro raízes para se referir a "neve" listando sete termos, e as análises de Martin e Pullum são bastante acuradas e precisas ao mostrar que, a partir daí, os números variaram de forma selvagem, de quatro ou sete a várias centenas (loc. cit.). No entanto, continua Pullum, mesmo o inglês teria diversas raízes para denotar "neve", e mesmo os especialistas nas línguas esquimós não são unânimes em apresentar um número fixo de termos para "neve", simplesmente porque a língua possui um mecanismo morfossintático capaz de gerar muitas formas via flexão e derivação, e nem todas diretamente identificáveis como

\footnotetext{
${ }^{7}$ Nos dois livros posteriores de Pinker (2004 e 2007) encontramos uma laboriosa refutação do RL com bases na ciência cognitiva.

${ }^{8}$ Que, no filme, seria operado pela personagem da atriz mencionada. A metáfora é pop, mas muito interessante: poucos leram efetivamente os textos de Whorf, mas muitos gostam de derivar coisas críticas negativas ou teorias incríveis a partir deles. Um só pesquisador sério não conseguiria limpar o caminho das crias (negativas ou positivas) de Whorf para despi-lo das armaduras e máscaras póstumas.
} 
"neve" (como temos, por exemplo, em neve, nevasca, nevado etc.) Nas palavras de Pullum,

\begin{abstract}
Perceba-se que a proposição de Whorf ${ }^{9}$ inflacionou os quatro termos de Boas para pelo menos sete (1: "caindo", 2: "no chão", 3: "endurecida", 4: "lamacenta", 5: "voadora", 6, 7 [sic]: "e outros tipos de neve"). Note-se também que suas afirmações sobre os falantes de inglês são falsas; eu me lembro da substância em questão ser chamada de neve quando fofa e branca, "slush" ["neve lamacenta"?] quando parcialmente derretida, "sleet" ["granizo"?] quando cai em um estado semi-derretido e "blizzard" ["nevasca"?] quando caindo forte o suficiente para tornar a direção uma coisa perigosa. O comentário de Whorf sobre sua própria comunidade de fala não é mais confiável do que as suas generalizações escorregadias sobre que coisas são "sensual e operacionalmente diferentes" ao esquimó genérico. (Pullum, 1991: 163)
\end{abstract}

Apesar da irreverência do texto de Pullum, o tema é bastante sério e diz respeito em grande parte à recepção posterior de Whorf não somente no que concerne ao problema do vocabulário de neve dos esquimós, mas sim ao fato problemático de se aceitar uma série de elementos de antropologia ou lingüística popular não somente como elementos de cultura geral mal digerida (ou, nos termos de Pinker, como absurdo convencional), mas, fundamentalmente, sobre a problemática do que Pullum identifica como "preguiça intelectual", ligada à ausência de evidências e argumentação sólida na apresentação de hipóteses importantes e tidas como científicas. Afinal, sobre a quantidade de palavras que os esquimós têm para "neve", afirma Pullum irônico, "nove, quarenta e oito, cem, duzentos, quem se importa? É um monte, certo?" (loc. cit., p. 165) ${ }^{10}$

\title{
2. O relativismo lingüístico e o etnocentrismo na sala de aula de LE
}

Como a visão descrita acima se relaciona com o ensino de línguas estrangeiras, afinal de contas? Ora, não é incomum que professores de línguas deparem com perguntas de alunos difíceis e complexas o suficiente para gerar situações delicadas. A percepção relativista algo próxima do senso comum de que as línguas são incomensuráveis entre si alia-se ao etnocentrismo às avessas que faz com que o

\footnotetext{
${ }^{9}$ Pullum refere-se a Whorf, 1956: 216.

${ }^{10} \mathrm{O}$ restante do texto procura mostrar o que de fato pode-se considerar como a quantidade de palavras que os esquimós têm para "neve". Um dicionário diz "duas", um especialista diz "algumas", mas com diversas ressalvas. A questão é, para Pullum, que não importa, pois até mesmo falantes de outras línguas podem ter o mesmo número de palavras ou mais, que daí decorrem duas coisas: (i) isso não diz quase nada sobre a estrutura do sistema conceitual dos esquimós e (ii) não importa, se você não for um esquimó que come banha de baleia e empresta suas esposas para estrangeiros (para a argumentação completa, cf. Pullum, 1991).
} 
professor de uma determinada língua estrangeira sinta-se mais "à vontade" falando a LE do que a sua própria língua, que sinta que a LE é mais agradável, mais bonita, que seus falantes são melhores, mais interessantes, que nos são superiores em muitas coisas, consciente ou inconscientemente. Moita Lopes (1996) discute essa questão em um livro que reúne artigos importantes para a abordagem do problema do modo como os professores de LE acabam assumindo a cultura do outro como sua, virando um modo de agentes colonizatórios agindo em favor do outro.

O resultado, muitas vezes, é a visão rasteira e de senso comum de que "o alemão é assim”, "na França é assado", "os gregos não têm palavra para isso porque são assim”. Muitos exemplos anedóticos podem ser arrolados: qualquer pessoa que já assistiu a várias aulas de alemão, por exemplo, já ouviu os alunos ou o professor associando o estereótipo do germânico rígido, pontual, austero ligado a questões da própria língua, como se a cultura moldasse a língua ou vice versa. Assim, não é incomum se ouvir em aulas de alemão, por exemplo, "o alemão tem palavra para tudo", "como eles conseguem marcar as horas desse jeito?" "que absurdo!", "nós brasileiros não fazemos assim porque somos mais preguiçosos e menos cuidadosos com a nossa língua", "o alemão tem o núcleo do sintagma nominal lá para trás [sic] da palavra porque os alemães são assim, mais fechados, introspectivos", entre outros "absurdos convencionais".

O problema está no modo como as pessoas mantêm concepções de linguagem muito estreitas como as mais apropriadas, e isso se intensifica quando os professores não percebem que eles mesmos compartilham de concepções preconceituosas, etnocentristas e deterministas sobre a linguagem da mesma forma que seus alunos (ou, ainda, às vezes, os próprios professores incutem tais visões em seus alunos). Uma visão interlingüística e intercultural e um estudo mais sistemático de língua, literatura e cultura que não valoriza mais a estrangeira do que a nativa melhoram a capacidade do professor de rebater as perguntas e opiniões preconceituosas e rasas de seus alunos com contra-exemplos, respostas mais elucidativas, elicitação de reflexão e discussão sobre o ponto em questão etc.

Parte do problema reside em algo que se pode chamar de "relativismo metodológico": os professores de línguas estrangeiras são moldados por tendências na metodologia de ensino, transportando para os seus alunos as visões de mundo que os seus formadores lhes apresentaram. Assim, como exemplo, uma sala de aula de contexto fortemente comunicativo, que proíba o uso de língua materna e de tradução e 
que se centre nas habilidades de produção e compreensão oral tende a criar uma "bolha lingüística" que favorece o isolamento do professor e do aluno no círculo opressivo da cultura do outro, gerando a necessidade de adesão aos padrões, conteúdos e métodos ligados àquele tipo de ensino, eliminando a possibilidade de flexibilização desses elementos em favor de um ensino mais voltado para os interesses e necessidades específicos desses alunos.

É assim que temos a sensação de que sempre estudamos sobre culinária, funcionamento de restaurantes, hotéis, táxis e manifestações culturais voltadas para o turismo, coisas interessantes e importantes instrumentalmente para os que estudam a LE para viajar para os países em que ela é falada e conseguirem algum nível de competência lingüístico-cultural de turista. Ora, há muitas outras necessidades envolvidas nos estudos de uma LE. Essa visão já bem estabelecida de que o estudo da língua estrangeira é "para falar" causa muita dúvida e inquietação em quem quer que me escute dar a resposta para "o que você faz": dizer que dou aula de latim quase sempre é seguido de uma pergunta adicional que pode ser selecionada entre as seguintes: "ah, então você fala latim?", “e é difícil falar latim?”, "mas quem fala latim ainda hoje?” ou ainda a melhor de todas: "então fala um pouquinho de latim para mim". Quando dou a resposta: "não, ninguém fala latim mais", o nível de confusão é extremo, e já não se sabe mais então por que motivo obscuro eu resolvi trabalhar com uma língua que "não serve para nada".

As pessoas por vezes se esquecem que uma língua representa uma cultura, uma literatura, um modo diferente de ver o mundo, e, acima de tudo, um modo diferente de construir a realidade. Isso tudo não precisa ser visto como uma "prisão diferente" para a qual você é transferido quando aprende uma outra língua. Antes, mais línguas, mais literatura, mais cultura, mais filosofia são, acima de tudo, a ampliação do próprio mundo do falante. Como dizia Humboldt já no século XIX:

O ser humano convive com os objetos principalmente, ou melhor, exclusivamente assim como a língua lhos introduz, devido ao fato de que o sentir e o agir nele dependem de suas idéias. Pelo mesmo ato pelo qual tece a língua para fora de si, ele se enreda e isola no tecido da mesma e cada língua desenha um círculo ao redor do povo ao qual pertence, do qual ele consegue sair apenas na medida em que se passa simultaneamente para o círculo de uma outra língua. $\mathrm{O}$ aprendizado de uma língua estrangeira, por isso, deveria ser a conquista de um novo ponto de vista na maneira anterior de ver o mundo, e de fato o é até certo grau, pois cada língua contém toda a teia de conceitos e o ideário de uma parte da humanidade. Este resultado apenas não é sentido de maneira pura e completa porque a própria 
visão do mundo e da língua é sempre transferida para a língua estrangeira, em maior ou menor grau. (Humboldt 2006: 149)

O relativismo, o etnocentrismo, a falta de reflexão sobre as concepções de linguagem que transcendam a simples e rasa idéia de que a língua é só um meio de comunicação, com o qual você pode usar um hotel, um restaurante ou um táxi são obstáculos para tornar-se um professor melhor. Vejamos alguns caminhos para fora das prisões estabelecidas por essas barras.

\section{Os caminhos para um professor livre das prisões da língua}

\subsection{O estudo da língua não pode se dissociar do estudo da lingüística}

A lingüística pode auxiliar o professor em diversos sentidos. O mais importante é aquele que ultrapassa a segmentação da formação prática afastada da teórica, ampliando as possibilidades de caminhos bibliográficos e vertentes de pensamento, conseguidos apenas com a recusa da submissão a modismos teóricos, e com o prevalecimento da curiosidade e do ecletismo na formação humanística do lingüistaprofessor. As escolas que seguem um só autor ou uma só linha de pensamento tendem a brigar com as outras, muitas vezes, por motivos mais sociológicos que efetivamente científicos. Uma boa olhada em bons textos de filosofia da ciência, filosofia da linguagem, filosofia da lingüística e história da lingüística podem auxiliar nesse sentido. (Borges Neto, 2004, Gonçalves \& Beccari, 2009; Rajagopalan, 2003 e 2004; Robins, 1981 etc.)

Outro ponto importante é que apenas o estudo sério da lingüística teórica nos vai possibilitar certas visões menos tendenciosas, preconceituosas e falhas sobre as questões da linguagem. Um exemplo anedótico pode ser contado aqui. Certa vez, eu via um professor falante nativo de português conversando com um círculo de alunos estrangeiros já fora da sala de aula. O professor contava com muito entusiasmo a eles que o português tem que "colocar uma vogal no final das palavras estrangeiras" porque, "nossas sílabas/palavras nunca acabam com consoantes". Ora, nada mais equivocado e mal-pensado. $\mathrm{O}$ estudo elementar de fonética e fonologia teria capacitado o professor a explicar o fenômeno do acréscimo de uma vogal ao final dessas palavras de modo adequado: nosso sistema fonológico não aceita consoantes oclusivas em final de 
sílaba/palavra, e por isso acrescentamos um núcleo silábico adicional para acomodar a palavra estrangeira à nossa língua. Não é nem mesmo necessário dizer que, de acordo com a "explicação" do professor, ele teria dificuldade em explicar o que acontece em "casas", "mar", "sal”, entre tantas outras palavras.

O estudo de fonologia auxilia na compreensão dos problemas de compreensão em produção oral, assim como o estudo da lingüística textual e de certas teorias da semântica, morfologia, sintaxe e pragmática auxiliam fortemente o professor a compreender melhor os processos de textualidade, inferência de significado de palavras pelo contexto semântico, morfológico, sintático, pragmático e passar a ensinar melhor as habilidades de compreensão e mesmo produção escrita.

Mas muito mais do que isso, a lingüística geral tem se debruçado sobre as questões fundamentais também para o ensino de línguas: a linguagem. Uma visão rasteira de linguagem continuará a entendê-la como uma capacidade simplesmente ligada a recepção e transmissão de informações, e o resultado é uma visão de língua como comunicação que é muito aquém do que a língua efetivamente pode fazer.

A reflexão sobre o modo como a linguagem de certa maneira cria o nosso mundo mental, segmentando as categorias que dão ordem ao mundo, só pode conduzir a uma visão de linguagem como atividade constitutiva (cf. Franchi, 2002, Gonçalves, 2008 e referências ali presentes). A linguagem é geradora de cosmovisão não no sentido negativo de que ficamos reféns da nossa língua e não podemos entender o mundo de outro jeito, mas, antes, a linguagem é geradora de modos de compreensão de que ampliam nossas capacidades de geração de modos de compreensão, numa espécie de efeito criativo que constrói a própria linguagem a cada momento enunciativo, ao mesmo tempo em que somos constituídos em nível de consciência a cada instante enunciativo. A linguagem pode criar e destruir, segmentar e tornar difuso, estabelecer e derrubar acordos, pactos e instituições. O enunciado performativo estabelece laços de matrimônio ou condena o acusado; os modos de fala causam dano ou júbilo ao outro e a si.

\subsection{O estudo da língua não pode se dissociar do estudo de outras línguas}

Não apenas outras línguas ampliam aquela capacidade constitutiva e criativa a que me referia na seção anterior, mas elas também são capazes de nos libertar do relativismo lingüístico e metodológico na posição de professores de LEs. Assim, mais 
uma vez com exemplo anedótico, um professor de uma língua moderna com casos morfossintáticos como o alemão, quando leciona sob o jugo da prisão metodológica moderna do comunicativismo, poderia se beneficiar enormemente do estudo de línguas que possuam mais casos morfológicos ou em que os casos exercessem um papel mais crucial, como as línguas clássicas (grego antigo, latim e sânscrito são uma boa pedida).

Não se advoga aqui que o professor de LEs precise aprender muitas línguas e se tornar um poliglota incômodo, que faz referências eruditas a muitas palavras e mecanismos de muitas línguas, mas, antes, que o professor entenda melhor os processos lingüísticos de sua língua e daquela que ensina a partir da ótica de quem olha para uma terceira, quarta ou x-ésima língua. As ampliações da cosmovisão poderão ajudar o professor de várias formas: ao entender os tipos de dúvidas, problemas, dificuldades tanto de alunos quanto de professores de uma língua que não é aquela que ele ensina, ele poderá se sentir muito mais à vontade para minorar as ansiedades de seus próprios alunos, quando muito freqüentemente não conseguem aceitar a diferença entre a sua própria língua e aquela que se está a ensinar, o que gera frustrações, dificuldades, bloqueios e desconfiança (por exemplo, quando o professor parece não saber responder a perguntas que nem sequer têm respostas convincentes - do tipo, mais uma vez anedótico, de coisas como "professora, por que woher tem acento na segunda e não na primeira sílaba?”).

\subsection{O estudo da língua não pode se dissociar do estudo da literatura e da cultura}

A defesa da cultura e da literatura aqui é mais ligada ao modo de emancipação e crescimento humanístico que seu estudo pode propiciar do que ao simples elenco de curiosidades antropológicas etnocêntricas e vazias que costumamos encontrar nos materiais de ensino de LEs modernas. As línguas são repositórios vivos e orgânicos de sistemas culturais, literários e filosóficos complexos, que as aulas de língua podem recuperar se conseguirem superar a barreira do elenco de trivialidades inúteis e cansativas que costumam constituir o que se chama de "cultura" nos materiais convencionais e "da moda" de ensino de línguas estrangeiras. Já há, no mercado editorial, materiais de ensino de línguas estrangeiras modernas que tentam seguir esse tipo de orientação enquanto mantém padrões metodológicos bem aceitos como a metodologia comunicativa, como o manual de ensino de alemão Blaue Blume, editado no Brasil pela Editora da Unicamp. 


\subsection{O estudo da língua não pode se dissociar do estudo da tradução}

A visão preconceituosa e irrefletida contemporânea de que se deve evitar a tradução no contexto da sala de aula de língua estrangeira é bastante negativa, especialmente porque mantém a bolha lingüística etnocêntrica às avessas do uso da língua estrangeira em contexto de quase imersão associado mais comumente à metodologia comunicativa.

A tradução pode ser muito mais benéfica do que danosa, se utilizada de modo apropriado em sala de aula, inclusive ao proporcionar reflexão comparativa entre línguas, criando o ambiente propício para a ampliação de visão de mundo discutida acima. A tradução lança luz sobre as diferenças e possibilita percepções que podem auxiliar na construção do conhecimento sobre a língua do outro a partir da percepção da própria língua. Ou ainda, conforme disse Humboldt,

(...) abstraindo das expressões que designam apenas objetos físicos, nenhuma palavra de uma língua é perfeitamente igual a uma de outra. Diferentes línguas são, deste ponto de vista, somente outras tantas sinonímias: cada uma delas exprime o conceito de um modo um pouco diferente, com esta ou aquela determinação secundária, um degrau mais alto ou mais baixo na escala das sensações. (Humboldt, 2001: 91)

\section{Considerações finais}

James L. Citron (1995) propõe o que ele chama de hipótese do relativismo etnolingual, segundo a qual um aprendiz de línguas estrangeiras que esteja menos restrito pela visão de mundo proveniente da sua própria língua pode ter maior sucesso ao aprender uma segunda língua. A questão colocada neste artigo envolve diversos tipos de problemas, como preconceitos, estereótipos e uma visão ingênua do processo lingüístico em si. Soluções possíveis passam por várias outras questões, como estimular a tolerância pela ambigüidade e incerteza, estimular a suspensão momentânea da própria identidade, repensar estratégias consolidadas de ensino de LE, de acordo com as tradições das línguas envolvidas, repensar o papel do professor como difusor colonizado-colonizador da cultura alienígena, estimular processos de comparação interlingüísticas através da relativização das diferenças, através do estímulo à tradução, 
da aceitação do diferente e do idiossincrático como fundamentais para compreensão do outro, entre outras.

\section{Referências}

BORGES NETO, José. Ensaios de Filosofia da Lingüística. São Paulo: Parábola Editorial, 2004.

CASSIRER, Ernst. A Filosofia das Formas Simbólicas. I - A Linguagem. Tradução: Marion Fleischer. São Paulo: Martins Fontes, 2001.

CITRON, James L. Can cross-cultural understanding aid second language acquisition? Toward a theory of ethno-lingual relativity. Hispania, Vol. 78. No. 1, 1995. pp. 105113.

FRANCHI, C. Linguagem - atividade constitutiva. Revista do Gel. Número Especial. p. 37-74, 2002.

GONÇALVES, R. T. Humboldt e o Relativismo Lingüístico. Estudos Lingüísticos, 35. São Paulo, 2006.

GONÇALVES, R. T. Perpétua prisão órfica ou Ênio tinha três corações: o relativismo lingüístico e o aspecto criativo da linguagem. Tese de doutorado, UFPR, 2008.

GONÇALVES, R. T.; BECCARI, A. J. Retórica e ciência: o caso da lingüística crítica. Revista Letras, 72, 2007.

GUMPERZ, John J.; LEVINSON, Stephen C (eds.). Rethinking Linguistic Relativity. Cambridge: Cambridge University Press, 1996.

HOLLIS, Martin \& LUKES, Steven (eds.) Rationality and Relativism. Cambridge, MA: MIT Press, 1982.

HUMBOLDT, Wilhelm von. Linguistic Variability and Intellectual Development. Translated by George C. Buck and Frithjof A. Raven. First Pennsylvania Paperback Edition. Philadelphia: University of Pennsylvania Press, 1972.

HUMBOLDT, Wilhelm von. Introdução a Agamêmnon (1816). In: Clássicos da Teoria da Tradução. Volume I: Alemão-Português. Organixado por Werner Heidermann. Florianópolis: Núcleo de Tradução da UFSC, 2001.

HUMBOLDT, Wilhelm von. Língua, Literatura e Bildung. Organizado por Werner Heidermann. Florianópolis: UFSC, 2006.

KAHANE, Henry and Renée. Humanistic Linguistics. Journal of Aesthetic Education, Vol. 17, No. 4, 1983. pp. 65-89. 
NEWTON-SMITH, W. Relativism and the possibility of interpretation. In: HOLLIS \& LUKE, 1982.

PINKER, Steven. O Instinto da Linguagem: Como a mente cria a linguagem. São Paulo: Martins Fontes, 2002.

PINKER, Steven. Tabula Rasa. A negação contemporânea da natureza humana. Trad. Laura Teixeira Motta. São Paulo: Companhia das Letras, 2004.

REGO, Gabriela de Azevedo Leão. O lugar da tradução no ensino de LEM. Monografia, UFPR, 2008.

SAPIR, Edward. A Linguagem: Introdução ao estudo da fala. Tradução: Mattoso Câmara Jr. Rio de Janeiro: Instituto Nacional do Livro, 1954.

SCHLEIERMACHER, Friedriech. Sobre os diferentes métodos de tradução (1813). In: Clássicos da Teoria da Tradução. Volume I: Alemão-Português. Organixado por Werner Heidermann. Florianópolis: Núcleo de Tradução da UFSC, 2001.

STEINER, G. Depois de Babel. Questões de Linguagem e Tradução. Tradução: Carlos Alberto Faraco. Curitiba: Editora da UFPR, 2005.

TRABANT, Jurgen. Humboldt ou le sens du langage. Liège: Mardaga, 1992.

WHORF, Benjamin Lee. Language, Thought, and Reality. Selected Writings of Benjamin Lee Whorf. Ed.: John B. Carroll. Cambridge, MA: The MIT Press, 1956. 